\title{
Students' Strategy in Connecting Fractions, Decimal, and Percent in Solving Visual Form Problems
}

\author{
Baiduri \\ Department of Mathematics Education, Universitas Muhammadiyah, Indonesia \\ Received July 15, 2020; Revised August 20, 2020; Accepted September 17, 2020
}

\section{Cite This Paper in the following Citation Styles}

(a): [1] Baiduri , "Students' Strategy in Connecting Fractions, Decimal, and Percent in Solving Visual Form Problems," Universal Journal of Educational Research, Vol. 8, No. 11, pp. 5361 - 5366, 2020. DOI: 10.13189/ujer.2020.081138.

(b): Baiduri (2020). Students' Strategy in Connecting Fractions, Decimal, and Percent in Solving Visual Form Problems. Universal Journal of Educational Research, 8(11), 5361 - 5366. DOI: 10.13189/ujer.2020.081138.

Copyright $\bigcirc 2020$ by authors, all rights reserved. Authors agree that this article remains permanently open access under the terms of the Creative Commons Attribution License 4.0 International License

\begin{abstract}
Fractions, decimals, and percentages are a rational number that is very important in mathematics and everyday life. However, there are still many students experiencing difficulties in understanding the concept due to its complexity in the scope of application and technical. Difficulty in understanding fractions and decimals will undoubtedly have implication for learning. This study aims to describe visual problem-solving strategies related to rational numbers of junior high school students in solving visual form problems. Descriptive research with a mixed approach was used for this purpose, with 32 students of grade VII in the middle school consisting of 10 (31.25\%) boys, and 22 (68.75\%) girls were used as research subjects. Data obtained through the subject has written answers to four questions in the form of visuals, namely one question determines the fraction, decimal, and percent values of a shaded area and three questions make up an area if a fraction, decimal, and percent value is given and the relationships among of them, which are then analyzed descriptively. The analysis results show that the subject's strategy of connecting fractions, decimals, and percent using conceptual and arithmetic operations, has not utilized the visual images provided optimally. On the other hand, the visual model is very important in understanding abstract mathematical concepts. Thus, the use of multiple visuals in learning fractions, decimals, and percent should be a concern to the teacher, especially on the topic of fractions.
\end{abstract}

Keywords Decimal, Fraction, Percent, Problem Solving

\section{Introduction}

Rational numbers are the very thing in school mathematics. Several studies have shown a positive relationship between prior knowledge of rational numbers and advanced mathematical skills. Weak comprehension of rational numbers hinders involvement in a variety of middle and upper income jobs [1], [2]. Conceptual concepts of rational numbers (fractions, decimals, and percent) show more complexity than integers, both in the scope of application and the technical expertise needed to master the rational number system [3]. This subject is also a problem for elementary and secondary school students, since in general they have known and experienced about rational numbers outside of school [1], [4]. The new surge of fraction and decimal comprehension work is inspired by evidence that rational numbers are connected to advance mathematical learning, including algebra and probability [2], [5], [6].

The concepts of fractions and decimals are fundamental in the elementary and secondary school mathematics curriculum as a prerequisite for advanced mathematics, especially algebra, and to succeed in many professions [7][9]. Unfortunately, mastery of fractions and decimals still poses great difficulties for students [7], [10], [11]. There are two types of difficulties in dealing with fractions and decimal material: (1) difficulties inherent in fractions and decimals and (2) cultural contingent difficulties which can be reduced by increasing instruction and prior knowledge of students [11]. The difficulty of students understanding fractions and decimals is that integers are the most frequent and first type of numbers they know. Students should avoid 
conceptualizing fractions and decimals as in integers ${ }^{[12]}$, more complex than integers by having multiple representations [13]-[15], and students have less time with problems related to fractions and decimals [4].

Difficulty in understanding fractions and decimals will undoubtedly have implications for learning [10], [13], [16]. Ideally, when students learn numbers during elementary school, they are allowed to make many connections between integers, fractions, decimals, and percent, which supports them in deepening their understanding of proportionality and ratio [17]. However, the fact is that fraction and decimal instructions usually start at different levels, spanning several years, and are often taught separately [7], [18], [19], and without allowing students to make connections, which hinders their capability to completely comprehend rational numbers [4]. Learning rational numbers that emphasizes relational understanding and using representation is a matter of concern for the teacher [3]. Propaedeutic learning in fraction material is very instrumental in shaping the concept of mathematics in elementary schools, and students achieve significantly better learning outcomes compared to students who haven't yet used this approach. [16]

In an effort to reduce difficulties, provide appropriate experience to improve students' informal knowledge and develop awareness of more meaningful connectivity concepts and procedures; teachers should play a more involved and direct role in the learning process. [4] Helping students develop an understanding of important mathematical ideas is a constant challenge for teachers [20]. If teachers don't even have an in-depth understanding of basic topics, they don't always know how to interpret ideas and make them easy to understand, and they often fail to convey concepts to be understood by students [21]. Teachers with a poor understanding of rational numbers and operations involving fractions and decimals will be barriers for students in learning algebra [11]. Interventions using story problems provide a substantial advantage in learning fractions, decimals, and percentages [11]. Building a comprehension of the products with similar of rational numbers and the connection among fractions, decimals, and percentages by developing a visual model of rational numbers is very important [4]

Based on the fact that understanding the concept of rational numbers is of great importance and visual models can build a comprehension of the connection among fractions, decimals, and percent, then in this study using visual form problems in an effort to explore strategies that students do in determining fraction, decimal, and percent values and the relationship between the three. Problemsolving is one of the strategies in learning mathematics.

\section{Methods}

This study aims to describe visual problem-solving strategies related to rational numbers of junior high school students, without intervening on the subject. The type of research used is descriptive with a qualitative and quantitative approach [22]. The subject of the research is taken from grade VII which happened to be the only class in private middle school numbered 32 people (all students) consisting of 10 (31.25\%) boys, and 22 (68.75\%) girls. In addition, the research ignores the characteristics of students, such as mathematical ability.

The data in this study are the subject's problem-solving strategy obtained from the subject's written answers. Data collection instruments in the form of fraction test questions adopted from [20] consists of 4 questions, namely one question determines the fraction, decimal, and percent values of a shaded area and three questions make up an area if a fraction, decimal, and percent value is given and the relationships among of them which are presented in Table 1.

Furthermore, the data that has been obtained is analyzed descriptively by coding the truth of the subject's answers and problem-solving strategies in connecting fractions, decimals, and percentages associated with understanding concepts. 
Table 1. Research instruments

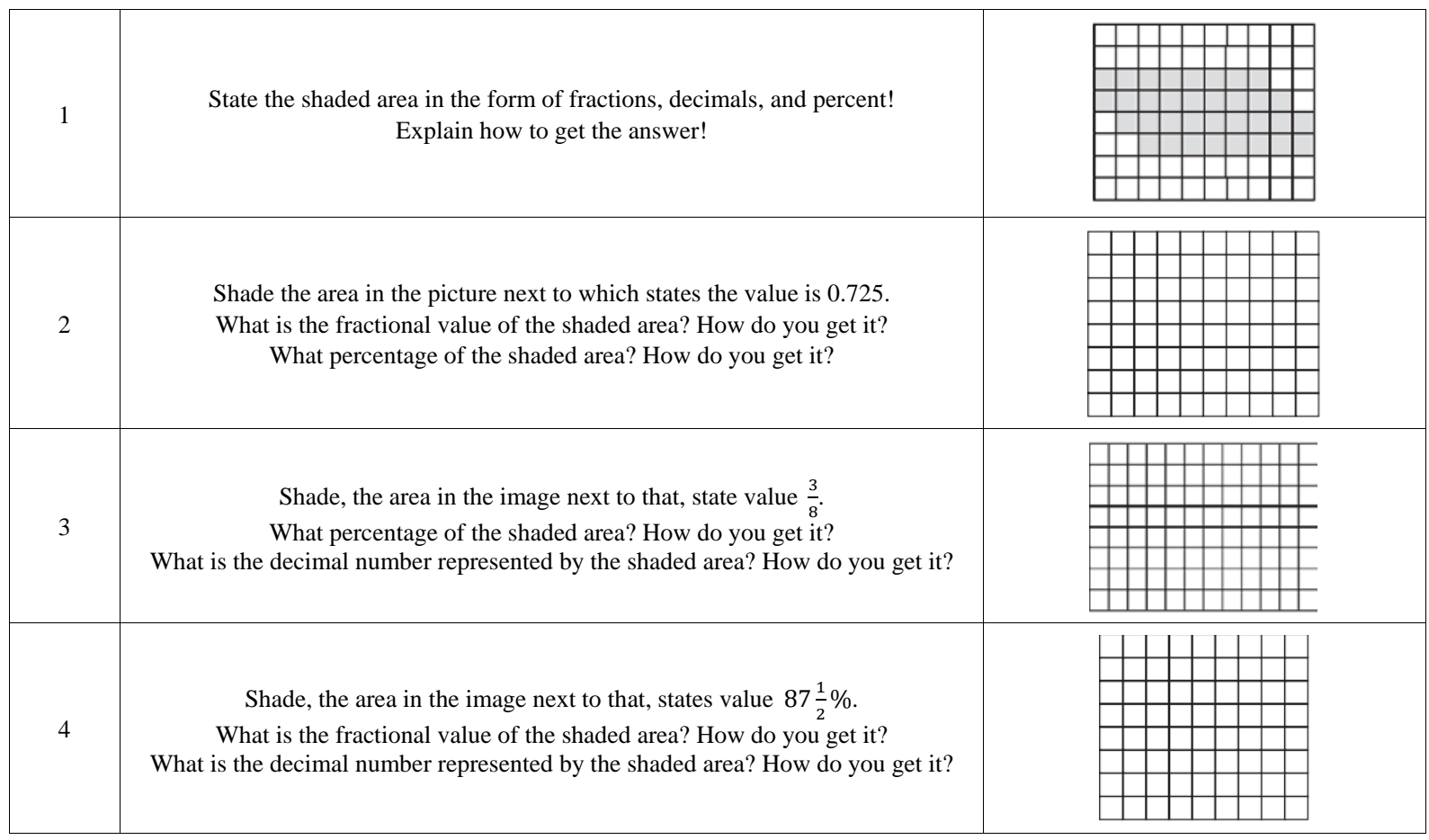

Table 2. Distribution of subject answers

\begin{tabular}{|c|c|c|c|c|c|c|c|c|}
\hline Gender & \multicolumn{2}{|c|}{ Problem number 1 } & \multicolumn{2}{|c|}{ Problem number 2 } & \multicolumn{2}{c|}{ Problem number 3 } & \multicolumn{2}{c|}{ Problem number 4 } \\
\hline & Right & False & Right & False & Right & False & Right & False \\
\hline Male & 10 & 0 & 5 & 5 & 5 & 5 & 5 & 5 \\
\hline Girl & 22 & 0 & 10 & 12 & 10 & 12 & 10 & 12 \\
\hline TOTAL & 32 & 0 & 15 & 17 & 15 & 17 & 15 & 17 \\
\hline
\end{tabular}

\section{Results and Discussion}

Based on the data obtained from the subject's written answers, the exposure to the results is presented in two parts: the frequency distribution of the correctness of the answers, and the subject's problem-solving strategies in connecting fraction, decimal, and percent.

\subsection{Distribution of Subject Answers}

The distribution of subject answers is presented based on the gender, question number, and right and false answers, as presented in Table 1.

Based on Table 1, for question number 1, declare fractions, decimals, and percent of the area shaded by the subject does not experience difficulties. All subjects can answer correctly. However, for questions, number 2 through number 4, grind the area if the fractional, decimal, and percent values are given the subject has difficulty. Female students experienced difficulties as much as $37.50 \%$ of the total subjects or $54.45 \%$ of the total female subjects. In comparison, male students experienced difficulties of $15.63 \%$ of the total subjects or $50.00 \%$ of the total male subjects. This result means that in solving problems from number 2 to number 4 , male subjects are better than female. This result is in line with the statement that males excellently in terms of mathematics and spatial ability while females excellent in terms of language and writing [23], [24]. The problem-solving strategies of the two are also different [25]-[27], males tend to be more flexible using more abstract strategies and retrieval, whereas females tend to use manipulative and more concrete strategies.

\subsection{Problem Solving Strategies and Connecting among Fractions, Decimals, and Percent}

\subsubsection{Problem Number 1}

The subject counts the number of shaded squares and the total number of squares to determine the fraction value of the shaded area. Next, create or write the fractional form and simplify it. In the given problem, 34 shaded squares are stating the numerator and 80 total stating the denominator. The fraction value obtained is

$$
\frac{34}{80}=\frac{17}{40}
$$


The subject's written answers are presented in Figure 1.

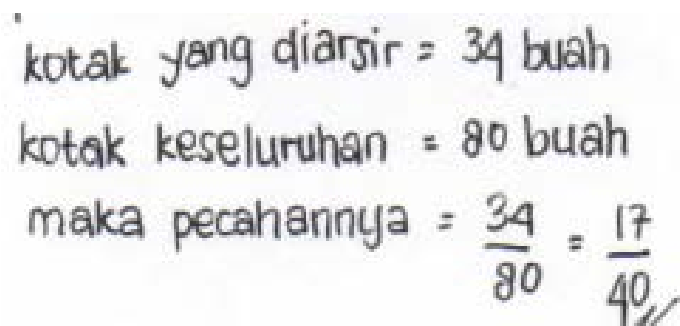

Figure 1. The subject's strategy determining the fractional value of the shaded area

This question was answered correctly by all subjects. That means that through the visual representation of images, the subject can understand the concept of fractions, part of the whole. Using of visual representations of images is an excellent way to present abstract ideas in mathematics, especially for students in primary education [4], [28], [29].

The subject performs a division operation to obtain a decimal value $\frac{34}{80}$ or $\frac{17}{40}$, so it gets 0.425 . This strategy is carried out by all subjects. While the strategy to find percent is done by multiplying operations, the decimal value $\mathrm{x} 100 \%$ and obtained $42.5 \%, 0.425 \times 100 \%$. All subjects also do this method. Another strategy undertaken by the subject is to perform multiplication operations of fraction values with $100 \%, \frac{17}{40} \times 100 \%=42,5 \%$.

\subsubsection{Problem Number 2 to Number 4}

The subject's strategy is to determine the number of squares to be shaded. First, the subject declares a decimal or percent value in the form of fractions. Second uses the equivalence of fractions to obtain a simpler fraction, and third, use the equivalence of fractions related to the number of squares in the picture. The numerator of the fractional value obtained states the number of squares to be shaded. These results are presented in Figure 2a. Another strategy is carried out by the subject after taking the first step or decimal, or percent value is multiplied by the many squares given in the image or by making an equation shown in Figure 2b.

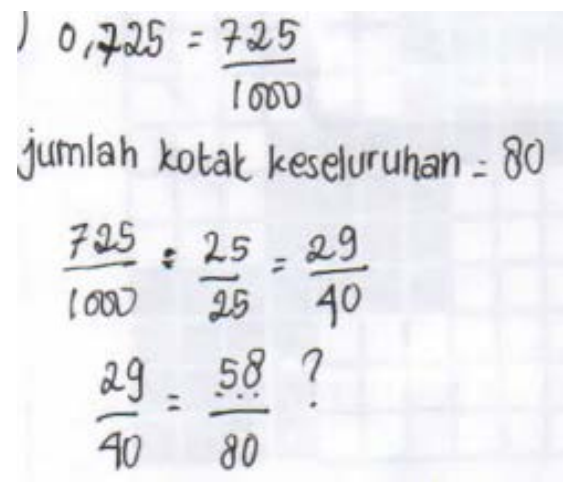

(2a)

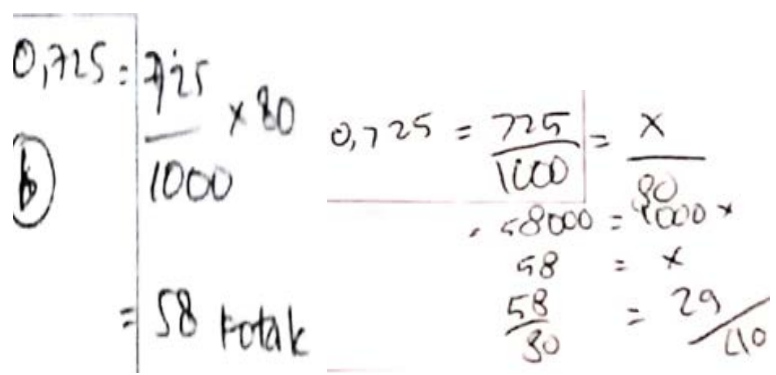

(2b)

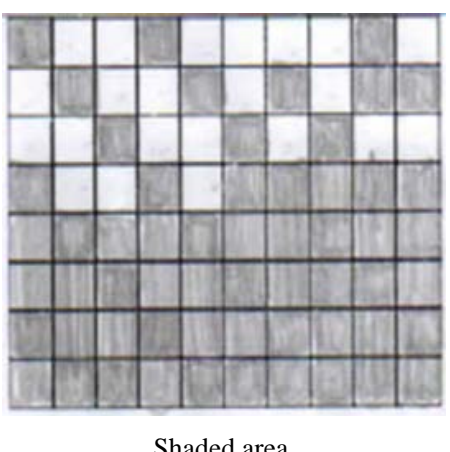

Figure 2. The subject strategy determines the area to be shaded in question number 2

This strategy shows that the subject does not understand well the concept of 1.00 (in decimal) and $100 \%$ of the given object. The new subject understands fractions, part of the whole. That is due in learning, decimal, and percent are taught separately with fractions and taught after learning fractions. This problem also happened in America, which is different from South Korea [1], [18], and the subject can apply fractional equivalence in solving problems [13].

The subject's strategy to connect the fractional value if given a decimal value using the decimal concept, which is divided by 10,100 , or 1000 (question number 2), then simplified with the concept of equivalent fractions, by dividing the numerator and denominator by the same number. Mathematically can be written,

$$
0,725=\frac{725}{1000} \div \frac{25}{25}=\frac{29}{49} \text {. }
$$

Meanwhile, to determine the percent value by multiplying the decimal or fraction value by $100 \%$, $0,725 \times 100 \%=72,5 \%$ or

$$
\frac{725}{1000} \times 100 \%=72,5 \% \text {. }
$$

This result shows that looking for percent values by moving the comma two steps to the right [20].

The subject's strategy to connect the decimal value and percent if the fractional value is known (problem number 3), by directly conducting fraction multiplication operations and $100 \%$,

$$
\frac{3}{8} \times 100 \%=37,5 \%
$$

and division 


$$
\frac{3}{8}=3 \div 8=0,375 \text { or } 37,5 \%=\frac{37,5}{100}=0,375 \text {. }
$$

These subjects who answered correctly understood the concept of percent, divided by 100 .

The strategy used by the subjects in determining percent in this study did not fully use the method of dividing the numerator and denominator and moving the comma two places to the right, or making fractions equivalent to the denominator of 100 , or assuming that the overall area presented was $100 \%$, determining the value percent for each square area [20].

The strategy used by the subject in connecting percent with a fraction (problem number 4), first divides the value of percent by 100 , then simplifies by dividing the numerator and denominator so that the desired fraction is obtained. Mathematically written,

$$
87 \frac{1}{2} \%=87 \frac{1}{2} \div 100=\frac{175}{2} \times \frac{1}{100}=\frac{175}{100} \div \frac{25}{25}=\frac{7}{8}
$$

Meanwhile, to connect with decimal by using the concept of percent $87,5 \%=\frac{87,5}{100}=0,875$ or using fraction division, $\frac{7}{8}=7 \div 8=0,875$. Overall the subject's strategy in connecting fractions, decimals, and percentages based on the computation of fractions, has not yet benefited the visuals given in the form of rectangles. Besides, in determining the decimal value, the subject can do easily by dividing the numerator and denominator or divided by 100 . This result is consistent with previous research that decimal is easier to master and students' performance on problems involving decimals are more reliable and quicker than fraction-related problems [1], [2], [5], [12].

In general, the subject's strategy of connecting fractions, decimals, and percent is by the meaning of numbers conceptually. Fractions, decimals, and percent is one notation of rational numbers. Mastering all three can be said to have understood rational numbers. The importance of understanding rational numbers for students' performance and future work, a deep misunderstanding of fraction, decimal, and percentage arithmetic is a serious issue [11]. One aspect that determines the effectiveness of learning rational numbers is how the sequence of notations is taught. Rational numbers are complicated constructs because they can be represented in various symbols, and since each symbols have a variety of interpretations [1], [11]. It is not easy for students to grasp all meanings of a rational number notation, let alone expand the interpretation from one notation to another. Learning rational numbers in percentage order first, then decimal, and the last fraction produces better results than the traditional sequence, where fractions are taught first [1]

\section{Conclusions}

The concepts of fractions, decimals, and percent for school students are very important because these topics are very complex and essential for learning other mathematical materials and are widely used in daily life. The strategy is used by junior school students to express fractions, decimals, and percent of the visual representation of a given image by counting the many shaded areas (as a numerator) and calculating all regions (as a denominator). After the fraction is obtained, the strategy subject connects to decimal by dividing the numerator and denominator, while to connect to percent by multiplying fractions by $100 \%$.

The problem-solving strategy of determining (shading) an area if given a fraction, decimal, and percent is done by connecting decimal or percent to fractions, making equivalent fractions based on the many regions that are made as denominators and numerators of fractions that are equal to the number the area to be shaded or to carry out the fraction, decimal, and percent multiplication and the number of square multiplications given. The strategy for connecting percent to decimal or fraction is to divide the value of percent by 100, instead of connecting the decimal or fraction to percent by multiplying it by $100 \%$.

Junior school students undertake the strategies to connect among fractions, decimals, and percentages still underlie arithmetic and fraction arithmetic operations, not yet optimally utilizing the visual images provided. On the other hand, the visual model is very important in understanding abstract mathematical concepts. Therefore the use of multiple visuals in learning fractions, decimals, and percent should be of concern to the teacher, especially on the topic of fractions.

\section{REFERENCES}

[1] J. Tian and R. S. Siegler, "Which Type of Rational Numbers Should Students Learn First?,” Educ. Psychol. Rev., vol. 30, no. 2, pp. 351-372, 2018, doi: 10.1007/s10648-017-9417-3.

[2] M. DeWolf, M. Bassok, and K. J. Holyoak, "From rational numbers to algebra: Separable contributions of decimal magnitude and relational understanding of fractions,” J. Exp. Child Psychol., vol. 133, pp. 72-84, 2015, doi: 10.1016/j.jecp.2015.01.013.

[3] B. Brown, "The relational nature of rational numbers," Pythagoras, vol. 36, no. 1, pp. 1-8, 2015, doi: 10.4102/pythagoras.v36i1.273.

[4] C. Scaptura, J. Suh, and G. Mahaffey, "Masterpieces to Mathematics : Using Art to Teach Fraction, Decimal, and Percent Equivalents,” Math. Teach. Middle Sch., vol. 13, no. 1, pp. 24-28, 2007.

[5] M. Hurst and S. Cordes, "Rational-number comparison across notation: Fractions, decimals, and Whole Numbers," J. Exp. Psychol. Hum. Percept. Perform., vol. 42, no. 2, pp. 281-293, 2016, doi: 10.1037/xhp0000140.

[6] M. Hurst and S. Cordes, "A systematic investigation of the 
link between rational number processing and algebra ability,” Br. J. Psychol., vol. 109, no. 1, pp. 99-117, 2017, doi: 10.1111/bjop.12244.

[7] M. A. Hurst and S. Cordes, "Children's understanding of fraction and decimal symbols and the notation-specific relation to pre-algebra ability,” J. Exp. Child Psychol., vol. 168, pp. 32-48, 2018, doi: 10.1016/j.jecp.2017.12.003.

[8] P. L. Nguyen, H. T. Duong, and T. C. Phan, "Identifying the concept fraction of primary school students: The investigation in Vietnam," Educ. Res. Rev., vol. 12, no. 8, pp. 531-539, 2017, doi: 10.5897/err2017.3220.

[9] F. Reinhold, S. Hoch, B. Werner, J. Richter-Gebert, and K. Reiss, "Learning fractions with and without educational technology: What matters for high-achieving and low-achieving students?,” Learn. Instr., vol. 65, no. 101264, pp. 1-19, 2020, doi: 10.1016/j.learninstruc.2019.101264.

[10] J. A. J. Danan and R. Gelman, "The problem with percentages,” Philos. Trans. R. Soc. B Biol. Sci., vol. 373, no. 20160519, pp. 263-273, 2018, doi: 10.1017/9781316659250.015.

[11] H. Lortie-Forgues, J. Tian, and R. S. Siegler, "Why is learning fraction and decimal arithmetic so difficult?," Dev. Rev., vol. 38, pp. 201-221, 2015, doi: 10.1016/j.dr.2015.07.008.

[12] T. Iuculano and B. Butterworth, "Rapid communication Understanding the real value of fractions and decimals," Q. J. Exp. Psychol., vol. 64, no. 11, pp. 2088-2098, 2011, doi: 10.1080/17470218.2011.604785.

[13] L.-K. Kor, S.-H. Teoh, S. S. E. Binti Mohamed, and P. Singh, "Learning to Make Sense of Fractions: Some Insights from the Malaysian Primary 4 Pupils," Int. Electron. J. Math. Educ., vol. 14, no. 1, pp. 169-182, 2018, doi: 10.29333/iejme/3985.

[14] L. S. Fuchs, A. S. Malone, R. F. Schumacher, J. Namkung, and A. Wang, "Fraction Intervention for Students With Mathematics Difficulties: Lessons Learned From Five Randomized Controlled Trials,” J. Learn. Disabil., vol. 50, no. 6, pp. 631-639, 2017, doi: 10.1177/0022219416677249.

[15] S. Getenet and R. Callingham, "Teaching fractions for understanding: addressing interrelated concepts,” The 40th Annual Conference of the Mathematics Education Research Group of Australasia: 40 Years On: We Are Still Learning! (MERGA40), 2017, pp. 277-284.

[16] B. Lazić, S. Abramovich, M. Mrđa, and D. A. Romano, “On the Teaching and Learning of Fractions through a Conceptual Generalization Approach," Int. Electron. J. Math. Educ., vol. 12, no. 8, pp. 749-767, 2017, doi: 10.13140/RG.2.2.21436.13448.

[17] J. HUI and K. PETTIGREW, “THE TREASURE CHESTS:
EXPLORING RELATIONSHIPS DECIMALS, AND PERCENTS AMONG FRACTIONS, DECIMALS, AND PERCENTS,” OAME/AOEM Gaz., no. March, pp. 1-2, 2020, doi: 10.1007/s10964-013-9948.

[18] H. S. Lee, M. DeWolf, M. Bassok, and K. J. Holyoak, "Conceptual and procedural distinctions between fractions and decimals: A cross-national comparison,” Cognition, vol. 147, pp. 57-69, 2016, doi: 10.1016/j.cognition.2015.11.005.

[19] M. Rapp, M. Bassok, M. DeWolf, and K. J. Holyoak, "Modeling discrete and continuous entities with fractions and decimals,” J. Exp. Psychol. Appl., vol. 21, no. 1, pp. 4756, 2015, doi: 10.1037/xap0000036.

[20] M. S. Smith, E. A. Silver, and M. K. Stein, Improving Instruction in Rational Numbers and Proportionality. Teachers College, Columbia University New York. 2005.

[21] R. Rosli, D. Goldsby, A. J. Onwuegbuzie, M. M. Capraro, R. M. Capraro, and E. G. Y. Gonzalez, "Elementary preservice teachers' knowledge, perceptions and attitudes towards fractions: A mixed-analysis,” J. Math. Educ., vol. 11, no. 1, pp. 59-76, 2020, doi: 10.22342/jme.11.1.9482.59-76.

[22] Sugiyono, Metode penelitian kuantitatif, kualitatif, dan $R \& D$. Bandung: Alfabeta. 2016.

[23] M. Asis, N. Arsyad, and Alimuddin, "Profil Kemampuan Spasial Dalam Menyelesaikan Masalah Geometri Siswa Yang Memiliki Kecerdasan Logis Matematis Tinggi Ditinjau Dari Perbedaan Gender,” J. Daya Mat., vol. 3, no. 1, pp. 78-87, 2015, doi: 10.26858/jds.v3i1.1320.

[24] F. van Nes and M. Doorman, "Fostering young children's spatial structuring ability," Int. Electron. J. Math. Educ., vol. 6, no. 1, pp. 27-39, 2011.

[25] Baiduri, "Profil Berpikir Relasional SIswa SD dalam Menyelesikan Masalah Matematika Ditinjau dari Kemampuan Matematika dan Gender. Disertasi: PPS Universitas Negeri Surabaya,” 2013.

[26] S. M. Reis and S. Park, "Gender differences in high-achieving students in math and science," J. Educ. Gift., vol. 25, no. 1, pp. 52-73, 2001, doi: $10.1177 / 016235320102500104$.

[27] A. M. Steegh, T. N. Höffler, M. M. Keller, and I. Parchmann, "Gender differences in mathematics and science competitions: A systematic review,” J. Res. Sci. Teach., vol. 56, no. 10, pp. 1431-1460, 2019, doi: 10.1002/tea.21580.

[28] Baiduri, "Understanding of Fraction Concepts of Elementary School Students Through Problem Solving," 2020.

[29] C. Bruce, S. Bennett, and T. Flynn, "Rational Number Teaching and Learning - Literature Review,” 2018. 